Human Ethology Bulletin - Proc. of the V. ISHE Summer Institute (2016): 47-59

Theoretical Review

\title{
Proximate AND Ultimate FaCtors in Evolutionary THINKING ON ART
}

\author{
Eveline Seghers \\ Department of Art, Music and Theater Studies, Ghent University, Belgium. \\ es.seghers@gmail.com
}

\begin{abstract}
Art is often described as an evolutionary adaptation, but not enough thought has been given to arguments in support of this claim. This can lead to a variety of explanatory issues, such as unjustly describing artmaking as an adaptation, not recognizing its complex nature, and its potentially even more complex evolutionary trajectory. This paper addresses one subject in particular, which is the conceptual distinction between ultimate and proximate levels of explanation. More specifically, this brief analysis investigates to what extent functional, adaptive explanations and proximate mechanisms might be confused, leading to strong adaptationist claims that may not be in accordance with the available evidence. In this paper, two hypotheses are discussed from this perspective, and it is argued that both of them, upon closer and more extensive analysis, might not stand the adaptationist test.
\end{abstract}

Keywords: Art, adaptation, proximate mechanisms, ultimate explanations, methodology.

\section{INTRODUCTION}

Current research on the evolutionary origins of visual art consists of a number of different disciplinary approaches, various ascribed functions, and vivid debates on the question whether artmaking should at all be regarded as a functional behaviour. Alternative proposals 
Seghers, E.: Proximate and Ultimate Factors in Evolutionary Thinking on Art Human Ethology Bulletin - Proc. of the V. ISHE Summer Institute (2016): 47-59

include art as a byproduct, an exaptation, and an outcome of gene-culture co-evolution (e.g. Boyd \& Richerson, 1985; Pinker, 1997), yet few authors converge on a most likely evolutionary account for art's origins. Even among those agreeing about art's presumed adaptive nature, significant disagreement arises when its precise adaptive function is at stake. This paper looks at the argumentative structure of adaptationist hypotheses, i.e. the soundness of the arguments put forward in favour of artmaking as an evolved functional trait, by focussing on the matter of proximate and ultimate levels of explanation. According to Tinbergen (1963), processes responsible for the full manifestation of a trait unfold at a proximate level, referring to the ontogenetic development of the trait and the concrete mechanisms enabling its functioning, as well as at an ultimate level, containing both phylogenetic causation and an explanation as to the adaptive function of the trait. Adaptationist accounts of art - i.e. explanations of art's emergence for a functional effect - are traditionally concerned with the ultimate level. After mentioning four major adaptationist accounts of art, I discuss the examples of the ancestress hypothesis and the simulation hypothesis. These are prime examples of hypotheses where the distinction between the ultimate and proximate level of explanation may not take place to a sufficient extent, leading to the attribution of functional adaptationist claims to art, where these might not be justified by the structure of the explanatory hypotheses in themselves. The paper concludes with a brief discussion, highlighting several ways in which the present analysis could be framed within a wider context of evolutionary research on art.

\section{ART AS AN ADAPTION}

\section{Adaptationist hypotheses of art}

The artification hypothesis (Dissanayake, 1995, 2008) involves an ethological assessment of the universal human propensity for artifying ordinary reality, a practice often referred to as 'making special' (e.g. 1995). Such artification may variously consist of applying visual motives to objects and human bodies, adding elements such as rhythm and melody to ordinary speech in order to turn it into song, and introducing narrative patterns and rhyme into factual, verbal accounts of events, turning them into storytelling of an often elaborate nature. Artmaking is seen as an evolved behavioural propensity that highlights communityrelevant information and elicits prosocial emotions, in turn strengthening group cohesion. Coe (Aiken \& Coe, 2004; Coe, 1992, 2003) equally adopts an ethological, cultural anthropologically-inspired framework when proposing that visual art is closely intertwined with maternal lines of descent. Art, broadly defined as the application of colour, form and pattern to objects or bodies, aids in identifying conspecifics who are codescendants, i.e. who are offspring of the same maternal ancestor. This ancestor may be in a distant past, or may even be metaphorical, such as in the case of an ancestor conceptualized within a religious framework of myths of origin. Art's ultimate function is to identify relatedness with conspecifics and to establish cooperative bonds, sometimes through the specific presence in art of messages that indicate desirable prosocial behaviour. 
In addition to ethology, art has been described as an adaptation from an evolutionary psychological point of view. The aesthetic fitness indicator hypothesis (Miller, 1999, 2001a, $2001 \mathrm{~b}$ ) proposes that artmaking evolved through sexual selection as a signalling trait of males, advertising their mate quality to females by means of the creation of high-cost aesthetic displays. Because making such displays requires a lot of skill and resources, those males displaying these characteristics more prominently are hypothesized to be in possession of various fitness indicators, and to gain a significant advantage over other males in terms of attracting and sustaining female attention, and eventually achieving female choice in their favour. The aesthetic fitness indicator hypothesis has received empirical support from larger-scale analyses of cultural production and demographic patterns (Miller 1999), as well as from more specific empirical set-ups (Clegg et al., 2011; Haselton \& Miller, 2006). Finally, evolutionary psychology has also produced a simulation perspective on the evolution of art. The simulation hypothesis can be regarded as an overarching term for a variety of evolutionary perspectives on art, mostly focussed on fictional storytelling, that propose that we evolved this and similar behaviours because they provide us with a functional means to develop our cognitive make-up and social cognition abilities. This in turn allows for aiding our daily interactions with others, and for several advanced cognitive processes such as mental time travel, anticipating future events, weighing different alternative actions, and so forth. Among the authors who have endorsed such views with regard to the emergence of storytelling are Gottschall (2012), Carroll (2005) and Boyd (2009), while Boyd and Carroll, in addition to Tooby and Cosmides (2001) have also developed insights that look at the arts more generally. The latter describe fictional art as an operational practice that will help, by means of the capacity for decoupling external and imagined representations, to gain insight into the minds of others. The imagined worlds of fiction also aid in envisaging alternative scenarios and options for future action, increasing one's own behavioural and mental catalogue. According to Boyd (2009), the arts in general and fiction in particular provide a training ground where the human mind can acquire and develop perceptual, cognitive and expressive skills, such as vision, movement, and social cognition. Carroll (2005), finally, endorses a similar perspective in arguing that the arts provide an emotionally saturated set of models for determining appropriate behaviour and for learning to assess the behaviour of others.

\section{The traditional adaptationist argument for art}

All of the abovementioned adaptationist hypotheses make use of the same type of argument, which is to map properties of art that are also thought to be characteristic of evolved adaptations. For example, it is commonly argued that artmaking is a universal behaviour that often bears significant costs to its maker, that it arises spontaneously among young children and is easily learnt, elicits pleasurable emotional experiences, and sometimes appears to involve specialized cognition (Boyd, 2009; Carroll, 2005; Coe, 1992; Dissanayake, 2008; Miller, 2001b; Tooby \& Cosmides, 2001). Yet all of these characteristics, while they may very well apply to artmaking, do not prove its proposed adaptationist nature. A behaviour 
Seghers, E.: Proximate and Ultimate Factors in Evolutionary Thinking on Art Human Ethology Bulletin - Proc. of the V. ISHE Summer Institute (2016): 47-59

can be adaptive but not universal, such as in the case of negative frequency dependent selection, or it can be universal but not adaptive, if it was a cross-culturally recurring byproduct of other, universal adaptations. Elements such as spontaneous emergence do not always fully recognize the importance of teaching and social learning (e.g. Verpooten, 2013), and the cognitive capacities in question, such as theory of mind, may be highly relevant in everyday social interaction, rather than being specifically evolved for art. Pleasurable experience, in turn, can equally accompany a byproduct account of art, as endorsed by Pinker (1997), while costliness in terms of material use, for example, or physical wellbeing in the case of body ornamentation, is fairly obvious for visual art, but not so much for music and storytelling (Verpooten, 2013). Alltogether, such arguments do not appear to adequately substantiate adaptationist claims. They presuppose a monolithic view of art where the aforementioned criteria would neatly apply to, but this does not correspond to the often recommended systematic application of evidentiary standards (e.g. Andrews et al., 2002). As a consequence, it is not clear to what extent other potential explanatory categories, such as byproduct or exaptation, could be clearly excluded (Verpooten, 2013). Moreover, they often do not recognize the vast complexity of the phenomenon of artmaking, which seems to require a more detailed analysis of the elements involved.

\section{REVALUING THE PROXIMATE-ULTIMATE-DISTINCTION IN EVOLUTIONARY RESEARCH ON ART}

Evolutionary psychology, in particular the Santa Barbara school that produced the landmark volume The Adapted Mind (Barkow et al., 1992), is often said to focus heavily on functional explanations for why cognitive mechanisms and their behavioural outcomes emerged during human evolutionary history. Many researchers point out that merely identifying a trait's function - why did it evolve - is not going to provide a complete picture (e.g. Boyd \& Richerson, 1985; Mithen, 2005; Verpooten, 2013). Often, they follow up on Tinbergen's four questions (1963), arguing that an evolved trait can only be understood by teasing apart the different levels of its explanation. When applied to art, phylogenetic features might be precursors of artistic behaviour such as play, or crude animal versions of human components of art, such as aesthetic sensitivity (e.g. Boyd, 2009; Dissanayake, 1995; Seghers, 2014). Such non-human animal antecedents are particularly interesting as they can provide insight into those eras of human behavioural and cognitive evolution that are far beyond the reach of present-day empirical studies, as has been developed, for example, for the evolution of stone tool use in relation to similar practices among extant non-human primates (e.g. McGrew, 2015). As for adaptive functions, art may correspond to any of the proposed functions, such as its being a fitness indicator, a tool for social bonding or group identification, or a means for cognitive enhancement. On the proximate level, ontogenetic development includes the emergence of drawing among young children, and the presence of cross-cultural regularities in these patterns. It might also address the interaction between 
Seghers, E.: Proximate and Ultimate Factors in Evolutionary Thinking on Art Human Ethology Bulletin - Proc. of the V. ISHE Summer Institute (2016): 47-59

innate properties at the basis of such reliable development, and environmental influences that affect how these will eventually manifest themselves (e.g. Thornhill, 1998). The mechanisms involved in art can be anything ranging from imagination, learning, relevant emotions, perceptual biases, psychological propensities for aesthetically responding to informationally saturated environmental cues, and a wide variety of culture-specific experiental features, all of which would contribute to the eventual manifestation of artmaking as a behavioural trait (e.g. Boyd, 2009; Eibl-Eibesfeldt, 1989; Thornhill, 1998).

According to Scott-Phillips et al. (2011), the ultimate and proximate level are quite commonly, but erroneously mixed up. This happens, for example, with behavioural inclinations that are thought to lie at the heart of cooperative interactions. Religion is often regarded as an adaptation because of its potential to elicit cooperation, for example through enforcement mechanisms such as belief in supernatural punishment (Alcorta \& Sosis, 2005; Bulbulia, 2004, Watts et al., 2015). Scott-Phillips et al. (2011) instead argue that cooperation, not religion is the primary behaviour to be explained. Even if religion was empirically shown to fulfill this goal, this would still not explain why cooperation manifested itself in the first place. In order to explain cooperation, previously described insights such as inclusive fitness are necessary. Inclusive fitness theory generally explains how some behaviours that appear altruistic may in fact benefit the proliferation of one's own genetic material, corresponding to a genecentric view of natural selection (Hamilton, 1964).

\section{The ancestress hypothesis}

A very similar issue might be present in Coe's ancestress hypothesis. As mentioned before, she outlines art's ultimate function as the identification of close and distant kin and the advertisement of prosocial values and behaviour, both of which should elicit increased levels of cooperation (1992, 2003; Aiken \& Coe, 2004). Its proximate mechanisms are the processing of colours, forms and patterns, and hormones and other bonding mechanisms responsible for the attachment of mothers and other caretakers to infants, which were subsequently co-opted in forming affiliative bonds between conspecifics. Elsewhere, she somewhat confusingly talks about a "proximate or immediate effect," (1992, p. 219, emphasis added) and describes this effect as objects becoming more noticeable through the addition of colour, form and/or pattern. The category of visual art should be understood here as relatively broad, containing various examples of artistic practices that allow for identity associations such as certain types of body ornamentation, a clear example of which would be particular kinds of pendants following recognizable styles. Alternatively, the hypothesis can account for larger-scale visual art as this might be especially suitable for fulfilling the function of prosociality instruction.

According to Coe, common explanations of cooperation, such as kin selection theory, reciprocal altruism and cultural group selection, fall short in accounting for cooperative bonds and actions in complex societies. Instead advocating an ultimate explanation for artistic traditions, she claims that visual art is particularly suitable to achieve this as it can culturally connect individuals that are only very distantly related. Hamilton's rule, on the 
Seghers, E.: Proximate and Ultimate Factors in Evolutionary Thinking on Art Human Ethology Bulletin - Proc. of the V. ISHE Summer Institute (2016): 47-59

other hand, predicts a positive correlation between cooperative investment and genetic relatedness between a donor and his beneficiary, as cooperative action would otherwise be selected against due to its deleterious effect on the donor's gene propagation (Hamilton, 1964). In order to accommodate this issue, Coe and colleagues have developed an "ancestor-descendant conflict," seen as a multigenerational extension of Trivers' parentoffspring conflict (Coe et al., 2010; Trivers, 1974). Instead of parental investment, ancestors' investment in their offspring's cooperative behaviour towards each other is here developed over multiple generations, sustained by traditions such as visual artmaking.

Although ancestor-descendant conflict does provide an extension of parent-offspring conflict, it still does not mediate the issue that gene-based natural selection should act against the genes involved in behavioural propensities that put a donor at a significant disadvantage. Coe then introduces a second modification of standard, gene-centric evolutionary biology by replacing genes by traits as the units of analysis. The traits in question are traditions, defined as "culturally inherited traits that persist, transmitted from parent to child," (2003, p. 158) and reproductive success needs to be measured over multiple generations: "(...$)$ the aim of behavior, evolutionarily speaking, was not to promote the survival and reproductive success of an individual, but of a lineage of individuals descending from a common ancestor. (...) the measurement of the success is in the number of descendants over generations, not immediate offspring." (Aiken \& Coe, 2004, p. 7) She substantiates this shift by arguing that selection operates on phenotypes, maintaining those variants that have gene-propagating effects. Theoretically, this is possible, and it has repeatedly been argued that the phenotype is the relevant level of analysis, rather than the genotype (for a discussion, see Huneman, 2007). Cultural traits in particular have also been described as potential units of analysis (e.g. O'Brien et al., 2010). Yet sustaining such a point of view raises the question whether natural selection remains an advisable framework for understanding art's evolution from an ancestress point of view. Perhaps mechanisms such as cultural transmission are instead the key to understanding the emergence and development of traditions as traits. Scott-Phillips et al. (2011) describe cultural transmission in itself as a proximate mechanism, which would lend further support to the possibility that the core elements of the ancestress hypothesis are located at the proximate level.

Of course the option theoretically remains that the arts, or visual art in particular, might be an adaptation for identifying kin and eliciting cooperative intent and action. For this to be true, however, artmaking should see its proposed function supported by empirical data, as well as displaying evidentiary criteria of special design (e.g. Andrews et al., 2002). Even if only considering the latter, significant issues arise. Criteria such as precision and efficiency of a trait with regard to its being a solution for a certain adaptive problem are poorly supported. Specific signs of kinship affiliation materialized in visual art or bodily adornment are relatively easy to fake, leaving the entire cooperative system vulnerable to freeriders. As Coe (1992) recognizes herself, considerable costs are often associated with ancestral artistic traditions. Making art requires various kinds of resources, not to mention the obvious health 
Seghers, E.: Proximate and Ultimate Factors in Evolutionary Thinking on Art Human Ethology Bulletin - Proc. of the V. ISHE Summer Institute (2016): 47-59

risks accompanying invasive practices such as scarification. Such findings, together with the above discussion of proximate mechanisms, appear to suggest that the ancestress hypothesis gravitates more towards a proximate level approach to art.

\section{The simulation hypothesis}

Researchers such as Tooby and Cosmides (2001), Boyd (2009), and Carroll (2005) agree that the arts in general, and fiction in particular, are adaptations with the principal function of providing a training ground for exercising the mind. Mental abilities such as imagination, episodic memory, theory of mind and decoupling ability are thought to be operational in fiction, and may be adaptations in themselves. Imagination, for instance, enables an individual to understand and anticipate situations that are yet to come, and to consider different possible alternatives for action within these situations (Tooby \& Cosmides, 2001). This would put the individual at an advantage compared to others, who might be less prepared upon dealing with unforeseen circumstances. The same goes for mental time travel, which can be seen as a combination of episodic memory and episodic future thinking (De Smedt \& De Cruz, 2011). Mental time travel would also be useful for future action. Foraging success, for example, would be greatly increased if hunter-gatherers could mentally anticipate patterns such as animal migrations and seasonal distribution of vegetation. Theory of mind, in turn, is particularly relevant for achieving insight into other people's minds, including their intentions and emotions. It is thought to result in greater empathy towards others (e.g. Baron-Cohen, 1995).

Authors endorsing the simulation hypothesis often claim that fiction is an adaptation because it exercises, and thus strengthens, capacities such as imagination, mental time travel and theory of mind (Boyd, 2009; Tooby \& Cosmides, 2001). Empirical evidence in support of this has shown constructive effects of reading fiction on empathy levels (Mar et al., 2009). It is possible, however, that the actual evolutionary trajectory of fiction took a non-adaptive pathway, and that engaging in fiction turns out to be, upon closer analysis, a proximate mechanism to meet more functional ends, which might be embodied in some of the cognitive mechanisms involved. Fiction could then encompass a byproduct of a variety of mental abilities such as the aforementioned examples, in the technical sense that, like all other traits, it is built upon pre-existing features of a species' cognitive, behavioural or anatomical architecture. As a byproduct, it could emerge and be sustained because of the pleasurable experience associated with it, as Pinker (1997) has pointed out.

This raises the question whether the assumption of causality in adaptationist thinking on fiction might have been erroneous. The simulation accounts of Boyd (2009), Tooby and Cosmides (2001) and Carroll (2005) broadly describe fiction as giving rise to, and strengthening imagination, but it is equally possible that the actual evolutionary trajectory operates in the other direction, i.e. after imagination arose in our ancestors' cognitive repertoire, fiction emerged as a non-adaptive spin-off. Fiction is sometimes said to contain specific structural properties such as events, agents and actions for their functional relevance in understanding the real world (e.g. Sugiyama, 2005), but it cannot be excluded that fiction 
merely contains these elements because they are already characteristic of everyday interaction. Storytelling, for example, would in this case not have evolved with the aim of acquiring better cognitive insight into conspecifics' actions and behaviour, but instead would have arisen by virtue of pre-existing insights in these domains. Of course the question remains why fictional storytelling would be practised as a proximate mechanism linked to, for example, imagination as an adaptation, i.e. why imagination should be put to work in an apparently non-functional context. Proponents of adaptationist explanations of fiction might argue that engaging in fiction does not appear to produce immediate worldly benefits, as cooperation does. As a consequence, fiction appears to be an end in itself, and not a proximate mechanism.

An answer to this might simply be a return to the simulation hypothesis in itself. According to Tooby and Cosmides (2001), fiction works as an operational adaptation, greatly enhancing our cognitive repertoire in various domains. A similar point is made by Boyd. While arguing that fiction is clearly an adaptation, fulfilling multiple functions, the main function all other functions come from, is that it provides a medium for mental practice (2009). Like Tooby and Cosmides, Boyd thus awards an operational function to fiction, albeit among several other, more general functions. This does not, however, automatically prove that fiction evolved as an adaptation to develop these skills further - a statement that in itself appears to suggest that functional relevance mostly applies to these abilities, rather than to fiction as such. Most interpretations of the simulation hypothesis do tend to state that fiction trains our behavioural and social repertoire, and not the applicable cognitive abilities in themselves (e.g. Boyd, 2009; Carroll 2005; Gottschall, 2012), with only Tooby and Cosmides (2001) endorsing a stronger computational perspective. Regardless of this, however, it is not clear how fiction would be necessary for developing properties such as imagination, as imagination in itself could accomplish this. In the case of theory of mind, it is also unsure to what extent fiction would comprise significant supportive effects, as theory of mind must ontogenetically precede the emergence of fictional storytelling, or children's variants such as pretend play. Such arguments make it more likely that fiction would qualify as a byproduct adopted as a proximate mechanism, rather than an adaptation in itself.

\section{DISCUSSION AND CONCLUSION}

This brief analysis illustrates that it is necessary to award more attention to the ultimateproximate distinction when developing adaptationist hypotheses of art. Doing so may lead, as Scott-Phillips et al. (2011) argue, to a recognition of the proposed ultimate explanations being instead located at the proximate level, i.e. among those factors that enable a functional goal, rather than encompassing this function in itself. This appears counterintuitive given the fact that functions such as social cohesion, cooperation, mate advertisement and choice, and cognitive elaboration are commonly presented as ultimate functions, but a perspective shift makes clear that this is not necessarily the case - an option explored above for both the 
Seghers, E.: Proximate and Ultimate Factors in Evolutionary Thinking on Art Human Ethology Bulletin - Proc. of the V. ISHE Summer Institute (2016): 47-59

ancestress and the simulation hypothesis. Researching ultimate and proximate factors involved in art's evolution therefore requires not only identifying which 'traditional' proximate mechanisms may have been at work, such as neurocognitive features and their relationship with evolutionary insights (e.g. Krill et al., 2007), but also whether the same is perhaps true for art's assumed ultimate functions. The emphasis on original adaptive functions in current evolutionary hypotheses of art may be partially due to a corresponding focus on the same matter in larger-scale frameworks, such as evolutionary psychology, that are prevalent in research on art (e.g. Buss et al., 1998). As a consequence, broadening the scope of analysis to include the proximate level of explanation would in turn yield new insights into the presently discussed hypotheses. Understanding processes of ontogenetic development in artmaking, for example, could illuminate the extent to which individuals are dependent upon environmental input for fully acquiring artistic skills, which can in turn be indicative of the relative role of cultural transmission processes in addition to innate propensities that are thought to lie at the heart of the proposed adaptive functions of art.

The fact that the ancestress hypothesis, like the artification hypothesis which also draws from research on cooperation and social bonding, is presented as being largely ethological in nature, also shows that placing oneself within an ethological framework does not automatically lead to a full recognition and adoption of key insights from this discipline, such as Tinbergen's four questions. On the other hand, it should be acknowledged that the four questions are in themselves located within a fairly traditional perspective of accounting for traits by means of the standard, genecentric conceptual repertoire of evolutionary biology and ethology. Some would argue that non-genetic inheritance is vastly underestimated in terms of its explanatory potential, and should not merely be seen as a set of proximate mechanisms within the overall whole (e.g. Mesoudi et al., 2013). This would then suggest that more integrated approaches such as gene-culture co-evolution would be a better starting point than, for instance, standard evolutionary psychology. Acknowledging different evolutionary forces and inheritance mechanisms might also enable a clearer insight into the nature of ultimate and proximate factors that could have been at work in art's evolution. This matter is particularly relevant given the fact that the ancestress hypothesis, for instance, already incorporates ideas that gravitate towards models of cultural evolution and transmission, although generally phrased in more traditional, genecentric terms.

Within the scope and limitations of this paper, a number of equally central concepts and issues were not treated. Among these are questions concerning the validity of the adaptationist explanations in themselves, i.e. whether the available evidence perhaps instead warrants a byproduct or an exaptationist explanation, how to treat artmaking as a replicable unit or a trait subject to an evolutionary explanation, whether several, sometimes strikingly different functions might have played a role in art's evolution, and which standards of evidence might apply to the complexity of this subject. One significant reason why various methodological matters currently interfere with acquiring more evolutionary insight into art, is that the realm of art being targeted by a specific hypothesis is very often not clarified. The components of both the proximate and ultimate level of explanation might, however, differ 
Seghers, E.: Proximate and Ultimate Factors in Evolutionary Thinking on Art Human Ethology Bulletin - Proc. of the V. ISHE Summer Institute (2016): 47-59

significantly depending on the type of art that should be explained. This is most obvious when contrasting general categories such as visual art and fiction, but can also apply when different types of visual art, for instance, are being studied, such as body ornamentation or painting. Recognizing the complexity of art as a whole, as well as its subcategories, should be one of the first steps towards developing more specific, testable hypotheses. Joining together all these elements would not only require extensive conceptual and methodological thought on this matter, but also a full integration with already available and yet to be developed empirical research.

\section{ACKNOLEDEGEMENT}

This work was previously presented during the 5th ISHE Summer Institute in Athens in May 2015. The author wishes to thank the organizers and attendants for their thoughtprovoking comments and questions, as well as Wilfried van Damme, Stefaan Blancke, and two anonymous reviewers for reading an earlier draft of this paper.

\section{REFERENCES}

Aiken, N.E., \& Coe, K. (2004). Promoting cooperation among humans: the arts as the ties that bind. Bulletin of Psychology and the Arts, 5, 5-20. DOI

Alcorta, C.S., \& Sosis, R. (2005). Ritual, emotion, and sacred symbols. The evolution of religion as an adaptive complex. Human Nature, 16, 323-359. DOI

Andrews, P., Gangestad, S.W., \& Matthews, D. (2002). Adaptationism - how to carry out an exaptationist program. Behavioral and Brain Sciences, 25, 489-553. DOI

Barkow, J.H., Cosmides, L., \& Tooby, J. (Eds.) (1992). The Adapted Mind. Evolutionary Psychology and the Generation of Culture. New York: Oxford University Press.

Baron-Cohen, S. (1995). Mindblindness. An Essay on Autism and Theory of Mind. Cambridge: MIT Press.

Boyd, B. (2009). On the Origin of Stories. Evolution, Cognition and Fiction. Cambridge: Harvard University Press.

Boyd, R., \& Richerson, P.J. (1985). Culture and the Evolutionary Process. Chicago: University of Chicago Press.

Bulbulia, J. (2004). Religious costs as adaptations that signal altruistic intention. Evolution and Cognition, 10, 19-38.

Buss, D.M., Haselton, M.G., Shackelford, T.K., Bleske, A.L., \& Wakefield, J.C. (1998). Adaptations, exaptations, and spandrels. American Psychologist, 53, 533-548. DOI

Carroll, J. (2005). Literature and Evolutionary Psychology. In. D.M. Buss (Ed.), The Handbook of Evolutionary Psychology (pp. 931-952). Hoboken: John Wiley \& Sons. DOI 
Seghers, E.: Proximate and Ultimate Factors in Evolutionary Thinking on Art Human Ethology Bulletin - Proc. of the V. ISHE Summer Institute (2016): 47-59

Clegg, H., Nettle, D., \& Miell, D. (2011). Status and mating success amongst visual artists. Frontiers in Psychology: Personality Science and Individual Differences, 2:310. DOI

Coe, K. (1992). Art: the replicable unit - an inquiry into the possible origin of art as a social behavior. Journal of Social and Evolutionary Systems, 15, 217-234. DOI

Coe, K. (2003). The Ancestress Hypothesis. Visual Art as Adaptation. New Brunswick: Rutgers University Press.

Coe, K., Palmer, A.L., Palmer, C.T., \& DeVito, C.L. (2010). Culture, altruism, and conflict between ancestors and descendants. Structure and Dynamics, 4, 1-17. Retrieved from https://escholarship.org/uc/imbs_socdyn_sdeas

De Smedt, J., \& De Cruz, H. (2011). The role of material culture in human time representation: calendrical systems as extensions of mental time travel. Adaptive Behavior, 19, 63-76. DOI

Dissanayake, E. (1995). Homo Aestheticus. Where Art Comes From and Why. Seattle: University of Washington Press.

Dissanayake, E. (2008). The arts after Darwin: does art have an origin and adaptive function? In. K. Zijlmans, \& W. van Damme (Eds.), World Art Studies. Exploring Concepts and Approaches (pp. 241-263). Amsterdam: Valiz.

Eibl-Eibesfeldt, I. (1989). Human Ethology. New York: Aldine de Gruyter.

Gottschall, J. (2012). The Storytelling Animal. How Stories Make Us Human. Boston \& New York: Houghton Mifflin Harcourt.

Hamilton, W.D. (1964). Genetical evolution of social behavior I and II. Journal of Theoretical Biology, 7, 1-52. DOI

Haselton, M.G., \& Miller, G.F. (2006). Women's fertility across the cycle increases the short-term attractiveness of creative intelligence. Human Nature, 17, 50-73. DOI

Huneman, P. (2007). Evolutionary theory in philosophical focus. In. W. Henke, \& I. Tattersall (Eds.), Handbook of Paleoanthropology (pp. 57-102). Berlin: Springer. DOI

Krill, A.L., Platek, S.M., Goetz, A.T., \& Shackelford, T.K. (2007). Where evolutionary psychology meets cognitive neuroscience: a précis to evolutionary cognitive neuroscience. Evolutionary Psychology, 5, 232-256. DOI

Mar, R.A., Oatley, K., \& Peterson, J.B. (2009). Exploring the link between reading fiction and empathy: ruling out individual differences and examining outcomes. Communications, 34, 407-428. DOI

McGrew, W.C. (2015). The cultured chimpanzee: nonsense or breakthrough? Human Ethology Bulletin - Proc. Of the XXII. ISHE Conference, 41-52.

Mesoudi, A., Blanchet, S., Charmantier, A., Danchin, E., Fogarty, L., Jablonka, E., Laland, K.N., Morgan, T.J.H., Müller, G.B., Odling-Smee, F.J., \& Pujol, B. (2013). Is non-genetic inheritance just a proximate mechanism? A corroboration of the extended synthesis. Biological Theory, 7, 189-195. DOI 
Seghers, E.: Proximate and Ultimate Factors in Evolutionary Thinking on Art Human Ethology Bulletin - Proc. of the V. ISHE Summer Institute (2016): 47-59

Miller, G. (1999). Sexual selection for cultural displays. In. R. Dunbar, C. Knight, \& C. Power (Eds.), The Evolution of Culture (pp. 71-91). Edinburgh: Edinburgh University Press.

Miller, G. (2001a). The Mating Mind. How Sexual Choice Shaped the Evolution of Human Nature. London: Vintage.

Miller, G. (2001b). Aesthetic fitness: how sexual selection shaped artistic virtuosity as a fitness indicator and aesthetic preferences as mate choice criteria. Bulletin of Psychology and the Arts, 2, 20-25. DOI

Mithen, S. (2005). The Singing Neanderthals. The Origins of Music, Language, Mind, and Body. London: Weidenfeld \& Nicolson.

O’Brien, M.J., Lyman, R.L., Mesoudi, A., \& VanPool, T.L. (2010). Cultural traits as units of analysis. Philosophical Transactions of the Royal Society B, 365, 3797-3806. DOI

Pinker, S. (1997). How the Mind Works. London: Penguin Books.

Scott-Phillips, T.C., Dickins, T.E., \& West, S.A. (2011). Evolutionary theory and the ultimateproximate distinction in the human behavioral sciences. Perspectives on Psychological Science, 6, 38-47. DOI

Seghers, E. (2014). Cross-species comparison in the evolutionary study of art: a cognitive approach to the ape art debate. Review of General Psychology, 18, 263-272. DOI

Sugiyama, M.S. (2005). Reverse-engineering narrative: evidence of special design. In. J. Gottschall, \& D.S. Wilson (Eds.), The Literary Animal. Evolution and the Nature of Narrative (pp. 177196). Evanston: Northwestern University Press.

Thornhill, R. (1998). Darwinian aesthetics. In. C. Crawford, \& D.L. Krebs (Eds.), Handbook of Evolutionary Psychology (pp. 543-572). Mahwah: Lawrence Erlbaum Associates.

Tinbergen, N. (1963). On aims and methods of ethology. Zeitschrift für Tierpsychologie, 20, 410-433. DOI

Tooby, J., \& Cosmides, L. (2001). Does beauty build adapted minds? Toward an evolutionary theory of aesthetics, fiction and the arts. SubStance, 30, 6-27. DOI

Trivers, R. (1974). Parent-offspring conflict. American Zoologist, 14, 249-264. DOI

Verpooten, J. (2013). Extending literary Darwinism: culture and alternatives to adaptation. Scientific Studies of Literature, 3, 19-27. DOI

Watts, J., Greenhill, S.J., Atkinson, Q.D., Currie, T.E., Bulbulia, J., \& Gray, R.D. (2015). Broad supernatural punishment but not moralizing high gods precede the evolution of political complexity in Austronesia. Proceedings of the Royal Society B, 282, 20142556. DOI 